\title{
Diretrizes para controle de informação documentada gerada pela implantação da NBR 15575: edificações habitacionais: desempenho em empresas construtoras
}

\author{
Guidelines for control of documented information \\ generated by the implementation of NBR 15575: \\ residential buildings: performance in construction \\ companies
}

\section{Simone Lazzarini Maria Aparecida Steinherz Hippert}

\section{Resumo

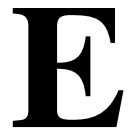

ste trabalho apresenta os resultados de uma pesquisa cujo objetivo foi propor diretrizes gerais para o controle de informação documentada gerada na implantação da NBR 15575 - Edificações habitacionais - Desempenho, em empresas construtoras, de forma a cumprir as exigências do requisito 7.5 Informação documentada, do Programa Brasileiro da Qualidade e Produtividade do Habitat (PBQP-H), e manter em arquivo os documentos referentes à obra. A metodologia adotada envolveu: 1) revisão bibliográfica sobre os temas "desempenho", NBR 15575 e PBQP-H; 2) estudo de caso em duas empresas, para identificar quais documentos estavam sendo gerados e como estavam sendo controlados. Os resultados apontaram várias dificuldades enfrentadas pelas empresas, como existência de checklists que não cumpriam seu papel; diferentes tipos de laudos de ensaios arquivados; ausência de definição de regras para controle e distribuição das informações, entre outras. Com base nessas constatações, são sugeridas diretrizes a serem seguidas de forma a diminuir essas dificuldades. Propõe-se também um checklist de verificação com prazos sugeridos de retenção de registros com base na vida útil de projeto (VUP) da NBR 15575.

Palavras-chave: NBR 15575. Norma de Desempenho. Informação documentada. SiAC PBQP-H. Implantação. Construtora. Edificação residencial.

\begin{abstract}
This paper presents the results of a research study aimed at proposing general guidelines for documented information control. That information is generated in the implementation process of Brazilian standard NBR 15575 in construction companies. The control is necessary to comply with the requirement 7.5 Documented information, of the Brazilian Habitat Quality and Productivity Program (PBQP-H) Regiment. The methodology adopted involved: 1) a bibliographic review on the themes "performance"; NBR 15575 and PBQP-H; 2) a case study was carried out in two companies, to identify

which documents were being generated and how they were being controlled. The results pointed out several difficulties faced by companies, such as the existence of checklists that did not fulfill their role; different types of archived test reports; absence of definition of rules for control and distribution of information, among others. Based on these findings, guidelines are suggested to be followed in order to reduce these difficulties. A checklist with suggested deadlines for retaining records based on the Project Lifetime (VUP) of NBR 15575 is also proposed.

Keywords: NBR 15575. Performance standard. Documented information. SiAC PBQPH. Implementation. Construction company. Residential building.
\end{abstract}

${ }^{1}$ Simone Lazzarini ${ }^{1}$ Universidade Federal de Juiz de Fora Juiz de Fora - MG - Brasil

${ }^{2}$ Maria Aparecida Steinherz Hippert ¿Universidade Federal de Juiz de Fora Juiz de Fora - MG - Brasil

Recebido em 29/10/19 Aceito em 27/04/20

LAZZARINI, S.; HIPPERT, M. A. S. Diretrizes para controle de informação documentada gerada pela implantação 


\section{Introdução}

Normas voltadas para o desempenho são estabelecidas buscando atender às exigências dos usuários e, no caso da NBR 15575 - Edificações habitacionais - Desempenho, em vigor desde julho de 2013, essas exigências se referem a sistemas que compõem edificações habitacionais, independentemente dos seus materiais constituintes e do sistema construtivo utilizado. $\mathrm{O}$ foco da norma está no comportamento em uso da edificação e não na prescrição de como os sistemas são construídos (ABNT, 2013).

O Programa Brasileiro da Qualidade e Produtividade do Habitat (PBQP-H) exige das construtoras o cumprimento da NBR 15575. Essa obrigação foi inserida no regimento do SiAC PBQP-H em 2017 e ratificada e expandida no regimento de 2018. Além de tornar obrigatória a existência de documentos ligados ao atendimento da NBR 15575, o regimento também determina que eles sejam controlados conforme regras específicas. Por outro lado, a NBR 15575 não especifica medidas para armazenamento ou controle das evidências geradas pelo seu atendimento pelas empresas. Pode-se citar, como exemplo dessas evidências, laudos de ensaios de materiais, laudos de ensaios da obra e projetos.

Nesse contexto, pesquisas realizadas recentemente (CÂMARA..., 2016; OTERO; SPOSTO, 2016) apontam que, apesar de preocupadas com as exigências da norma, as empresas ainda carecem de informações sobre o conteúdo do texto normativo e sua forma de aplicação; também indicam que a adesão à norma, apesar de ser vista como importante pelo mercado, é ainda um processo em andamento.

Por exemplo, Santos et al. (2016), em um estudo baseado em experimentação prática, propuseram-se a investigar como empresas de projeto e empresas construtoras estão trabalhando para a adoção de requisitos e critérios de desempenho de edificações, nas fases de elaboração de projetos e execução da obra. Os resultados da pesquisa levam, entre outras conclusões, à necessidade de orientação técnica às empresas que desejam implantar a norma.

Também Costella et al. (2017) realizaram um estudo cujo objetivo era avaliar o desempenho de edificações habitacionais de Chapecó, SC, por meio de um checklist. Os autores concluíram que as obras avaliadas não estavam atendendo à norma de desempenho como deveriam, mesmo considerando que foram estudadas obras e empresas de diferentes padrões. Constataram que todas apresentaram um nível de atendimento muito abaixo do esperado, não alcançando nem mesmo o desempenho mínimo exigido pela norma.

Por todos esses resultados, é possível perceber que o mercado, mesmo após seis anos de publicação da norma, ainda não a tenha adotado com a rapidez esperada dada a sua importância.

Considerando esse cenário, o presente trabalho tem por objetivo propor diretrizes para controle de informação documentada gerada pela implantação da NBR 15575 em empresas construtoras, de forma a cumprir as exigências do requisito 7.5 Informação documentada, do Regimento do Sistema de Avaliação da Conformidade de Empresas de Serviços e Obras (SiAC), e manter em arquivo, durante os prazos de vida útil, os documentos referentes à obra.

\section{Referencial teórico}

\section{NBR 15575: edificações habitacionais: desempenho}

Após a publicação da norma, em 2013, surgiram algumas iniciativas para facilitar o entendimento e a aplicação da NBR 15575 pelos profissionais da área, como o desenvolvimento de listas de verificação (checklists) de cumprimento dos requisitos. Esses checklists também tinham a função de orientar quais evidências de informação documentada eram necessárias para comprovar o cumprimento da norma.

O Grupo de Trabalho de Normas da Associação Brasileira dos Escritórios de Arquitetura (AsBEA) elaborou um checklist de atendimento à norma chamado Guia para Arquitetos na Aplicação da Norma de Desempenho, cujo objetivo é auxiliar os arquitetos na organização de seu trabalho, identificando o que é possível atender, o que necessita de aprofundamento e os itens nos quais é necessária a contratação de um consultor (ASSOCIAÇÃO..., 2019).

O Serviço Nacional de Aprendizagem Industrial de Minas Gerais (SENAI-MG), em parceria com o Sindicato da Indústria da Construção Civil no Estado de Minas Gerais (Sinduscon- MG), elaborou o Manual para Contratação de Projetos para o Desempenho de Edificações Habitacionais (SERVIÇO..., 2016). Esse trabalho se propôs a ser uma ferramenta eficaz para guiar as empresas na contratação e desenvolvimento dos projetos, além de permitir que as distintas especialidades sejam trabalhadas de maneira integrada. $\mathrm{O}$ guia foi desenvolvido para as diversas disciplinas (por exemplo, arquitetura, estrutura e instalações, entre outras). 
Para cada disciplina, leva em conta as diversas fases de projeto, desde a concepção do produto até o pósentrega da obra. Para cada fase e disciplina, o guia determina: quais são os produtos gerados; quais são as atividades desenvolvidas; que aspectos específicos da NBR 15575 devem ser observados pelos coordenadores de projeto e projetistas.

Outra iniciativa de sistematizar a norma em um checklist foi tomada pelo Programa de Inovação da Indústria da Construção Civil do Ceará (Inovacon-CE), com o apoio da CBIC e do SENAI. O documento "Análise dos Critérios de Atendimento à Norma de Desempenho NBR 15575" tem como objetivo auxiliar na elaboração dos projetos das edificações habitacionais, no seu planejamento e na sua execução, de forma a assegurar a conferência do atendimento de todos os requisitos e critérios exigidos pela norma (PROGRAMA..., 2016).

Uma terceira iniciativa a ser destacada é o trabalho realizado pelo grupo de pesquisa em Desempenho de Edificações liderado pelo Prof. Dr. Marcelo Fabiano Costella, da Universidade Comunitária da Região de Chapecó (Unochapecó, SC), consolidado em um livro, cujo objetivo é auxiliar construtores, incorporadores, projetistas e fornecedores a aplicarem os conceitos da norma. O livro apresenta uma seção de fundamentos de desempenho de edificações e, em seguida, uma discussão sobre cada requisito da norma, com a respectiva lista de verificação, que é o objetivo maior da publicação (COSTELLA, 2018).

A CBIC também decidiu organizar, com o apoio do IPT, um fórum virtual para esclarecimento de dúvidas. Após mais de um ano de funcionamento, as perguntas e respostas do fórum foram compiladas na publicação "Dúvidas sobre a norma de desempenho: especialistas respondem" (CÂMARA..., 2015).

Dentre as questões, uma abordava a retenção de evidências de cumprimento da norma, com o usuário do fórum perguntando sobre como seria verificado o atendimento dos requisitos da NBR 15575 pelo proprietário e pelos órgãos fiscalizadores. Os especialistas responderam que, caso houvesse dúvida pelo proprietário do apartamento sobre o cumprimento da norma pela construtora, ele poderia recorrer a ensaios e análises específicas (isolação acústica de fachadas, estanqueidade de pisos, etc.), a qualquer tempo dentro do prazo de vida útil. Completaram a resposta dizendo que, comprovado o não atendimento à norma, a construtora poderia ser responsabilizada, inclusive por propaganda enganosa e danos morais (CÂMARA..., 2015).

\section{Edificações habitacionais: desempenho e PBQP-H}

Entre os projetos do Programa Brasileiro de Qualidade e Produtividade no Habitat (PBQP-H) está o Sistema de Avaliação da Conformidade de Empresas de Serviços e Obras (SiAC), que tem como objetivo avaliar a conformidade do sistema de gestão da qualidade das empresas de serviços e obras, considerando as características específicas da atuação dessas empresas no setor da construção civil, e baseando-se na série de normas ISO 9000 (PROGRAMA..., 2019).

Para serem certificadas no SiAC, as empresas devem cumprir os requisitos definidos no Regimento Geral e no Regimento Específico da Especialidade Técnica Execução de Obras. Esses regimentos, em conjunto, definem as regras e a estrutura de funcionamento do $\mathrm{SiAC}$, além dos requisitos a serem verificados nas auditorias de certificação das empresas.

A exigência de cumprimento da NBR 15575 pelas construtoras aparece em várias seções do Regimento, conforme ilustrado no Quadro 1.

Por se tratar de uma norma técnica, a verificação de atendimento aos requisitos da NBR 15575 não será de competência das prefeituras municipais; ela será feita pelos interessados - proprietários, usuários, consumidores de um modo geral - e poderá ser necessária a sua comprovação, a qualquer tempo, em caso de dúvida ou discussão sobre a qualidade da construção e o cumprimento de obrigações para apurar responsabilidades. Por isso é importante a construtora manter em arquivo, durante os prazos de vida útil, os documentos referentes à obra (CÂMARA..., 2013).

Importante observar, com a exigência do requisito 8.4, a importância que o setor de suprimentos das empresas terá na verificação do cumprimento dos requisitos da norma pelo fornecedor. Os compradores terão uma nova responsabilidade ao solicitar e verificar laudos de ensaios e testes dos produtos que estejam adquirindo e que devam atender aos requisitos da NBR 15575. 
Quadro 1 - Exigências de cumprimento da NBR 15575 pelo Regimento do SiAC

\begin{tabular}{|c|c|}
\hline Requisito & Exigência \\
\hline $\begin{array}{l}\text { 8.1 Planejamento e } \\
\text { controle } \\
\text { operacionais da obra }\end{array}$ & $\begin{array}{l}\text { No caso de obras de edificações habitacionais, a elaboração do plano da } \\
\text { qualidade da obra deve considerar os requisitos de desempenho da NBR } 15575 \\
\text { definidos nos projetos da edificação [...] }\end{array}$ \\
\hline $\begin{array}{l}8.2 .2 \text { Determinação } \\
\text { de requisitos } \\
\text { relativos à obra }\end{array}$ & $\begin{array}{l}\text { No caso de obras de edificações habitacionais, a empresa construtora deve } \\
\text { considerar os requisitos de desempenho da NBR } 15575 \text { definidos nos projetos da } \\
\text { edificação. }\end{array}$ \\
\hline $\begin{array}{l}\text { 8.3.3 Entradas de } \\
\text { projeto }\end{array}$ & $\begin{array}{l}\text { Para o caso de obras de edificações habitacionais, a empresa construtora deve } \\
\text { determinar os níveis de desempenho - mínimo (M), intermediário (I) ou superior } \\
\text { (S), relativos aos seguintes requisitos dos usuários, conforme definido no item } 4 \\
\text { da NBR } 15575 \text { - Parte 1: Requisitos Gerais [...] }\end{array}$ \\
\hline $\begin{array}{l}\text { 8.3.4 Controles de } \\
\text { projeto }\end{array}$ & $\begin{array}{l}\text { Para o caso de obras de edificações habitacionais, a empresa construtora deve } \\
\text { considerar o atendimento dos requisitos de desempenho da NBR } 15575 \text {. }\end{array}$ \\
\hline $\begin{array}{l}\text { 8.3.5 Saídas de } \\
\text { projeto }\end{array}$ & $\begin{array}{l}\text { Para o caso de obras de edificações habitacionais, a empresa construtora deve } \\
\text { apresentar evidências dos meios definidos para o atendimento dos requisitos de } \\
\text { desempenho da NBR } 15575 \text {, considerando os níveis indicados no perfil de } \\
\text { desempenho da edificação (PDE), mediante análise de desempenho esperado das } \\
\text { soluções projetadas. }\end{array}$ \\
\hline $\begin{array}{l}\text { 8.4 Aquisição } \\
\text { 8.4.1 Generalidades }\end{array}$ & $\begin{array}{l}\text { No caso de aquisições para obras de edificações habitacionais, a empresa } \\
\text { construtora deve verificar a capacidade do fornecedor para atender os requisitos } \\
\text { de desempenho da NBR } 15575 \text {, com base nas informações por ele fornecidas. }\end{array}$ \\
\hline $\begin{array}{l}\text { 8.4.3 Informação } \\
\text { para fornecedores } \\
\text { externos }\end{array}$ & $\begin{array}{l}\text { No caso de obras de edificações habitacionais, os requisitos de processos, } \\
\text { produtos e serviços adquiridos externamente (de aquisição) especificados devem } \\
\text { considerar os requisitos de desempenho da NBR } 15575 \text { definidos nos projetos da } \\
\text { edificação. }\end{array}$ \\
\hline $\begin{array}{l}\text { 8.5.1 Controle de } \\
\text { produção e de } \\
\text { fornecimento de } \\
\text { serviço }\end{array}$ & $\begin{array}{l}\text { No caso de obras de edificações habitacionais, o manual de uso, operação e } \\
\text { manutenção deve levar em conta também as exigências da NBR } 15575 \text { - Parte } \\
\text { 1: Requisitos Gerais. }\end{array}$ \\
\hline $\begin{array}{l}\text { 8.6.1 Liberação de } \\
\text { materiais e serviços } \\
\text { de execução } \\
\text { controlados }\end{array}$ & $\begin{array}{l}\text { No caso de obras de edificações habitacionais, os procedimentos de inspeção e } \\
\text { monitoramento devem considerar os requisitos de desempenho da NBR } 15575 \\
\text { definidos nos documentos de aquisição [...]. A empresa construtora é dispensada } \\
\text { da realização de ensaios de recebimento de um lote específico do produto caso o } \\
\text { seu fabricante forneça relatório de ensaio demonstrando atendimento às } \\
\text { condições previstas nas normas de especificação e, no caso de edificações } \\
\text { habitacionais, na NBR } 15575 \text {, quando esta trouxer exigências complementares. }\end{array}$ \\
\hline
\end{tabular}

Fonte: Brasil (2018).

Além disso, o Regimento Específico, no requisito 7.5 Informação documentada, determina que o sistema de gestão da qualidade da empresa construtora deva incluir, relativo à NBR 15575, o perfil de desempenho da edificação e o plano de controle tecnológico de cada obra do escopo de certificação.

Também define as exigências a serem cumpridas para criação, atualização e controle destes, entre outros documentos. Ao criá-los e atualizá-los, a empresa deverá assegurar:

(a) que sejam identificados e descritos (por exemplo, um título, data, autor ou número de referência);

(b) que tenham um formato (por exemplo, linguagem, versão de software, gráficos) e um meio (por exemplo, papel, eletrônico) definidos; e

(c) que sejam analisados criticamente e aprovados quanto à adequação e suficiência.

Depois de criados, os documentos devem ser controlados, para que estejam disponíveis e adequados para uso, onde e quando forem necessários. Também devem estar suficientemente protegidos (por exemplo, contra perda de confidencialidade, uso impróprio ou perda de integridade). Por último, a empresa deve definir, para esses documentos, critérios para:

(a) distribuição, acesso, recuperação e uso; 
(b) armazenamento e preservação, incluindo preservação de legibilidade;

(c) controle de alterações (por exemplo, controle de versão); e

(d) retenção (tempo de guarda) e disposição (descarte adequado da informação) (BRASIL, 2018).

A preocupação básica dessa seção do Regimento é, portanto, garantir que a informação gerada na empresa, inclusive a relativa ao cumprimento da NBR 15575, esteja organizada e não se perca com o tempo.

\section{Método}

\section{Classificação da pesquisa}

Utilizando-se a classificação proposta por Prodanov e Freitas (2013), esta pesquisa é classificada como de natureza aplicada, com objetivos de pesquisa exploratória, utilizando-se de procedimentos de estudo de caso e pesquisa bibliográfica. Quanto à forma de abordagem do problema, a pesquisa pode ser classificada como qualitativa, pois não requer o uso de métodos e técnicas estatísticas.

\section{Etapas de execução da pesquisa}

A pesquisa foi feita em duas etapas: pesquisa bibliográfica e estudo de caso.

\section{Etapa I: pesquisa bibliográfica}

Foi realizada uma revisão de literatura focalizando quatro temas de interesse:

(e) o conceito de desempenho no mundo;

(f) o conceito de desempenho no Brasil;

(g) a NBR 15575; e

(h) a NBR 15575 e o PBQP-H.

Como a norma entrou em vigor em 19 de julho de 2013, e as discussões começaram alguns anos antes, a pesquisa foi limitada a uma janela de tempo de até 10 anos de publicação. A base de dados utilizada foi o Portal Periódicos CAPES.

Por se tratar de uma norma brasileira, as pesquisas foram feitas somente no idioma português. Ao final do processo, foi selecionado somente um artigo que se encaixava no objetivo da pesquisa (literatura sobre implantação da NBR 15575 em empresa construtora). O trabalho de Costella et al. (2017) tem como título "Avaliação da aplicação da norma de desempenho: estudo de caso em cinco empreendimentos".

Devido ao resultado insignificante de trabalhos selecionados, partiu-se para uma segunda etapa de pesquisa, tendo por base o trabalho de Hippert et al. (2018). Nesta pesquisa, os trabalhos foram estratificados por temas:

(a) conforto acústico;

(b) conforto térmico;

(c) segurança estrutural; e

(d) etc.

Alguns trabalhos (no total, 16 dissertações) não se enquadravam diretamente nesta classificação e foram alocados em uma categoria de "Tema Geral".

Adotando os mesmos critérios anteriores, foram selecionados 3 trabalhos (OKAMOTO, 2015; SILVA, 2016; SILVA JUNIOR, 2016), que se relacionam com o tema da pesquisa, mas que não tratam especificamente da implantação em construtoras. A leitura desse material pesquisado, no entanto, serviu de base para a busca de trabalhos neles referenciados, o que permitiu expandir a seleção inicial. Nessa etapa, não houve mais limitação de janela temporal, nem de idioma, tendo a leitura sido feita de documentos tanto em português quando em inglês.

Ao final dessa etapa, acrescentou-se 61 novos trabalhos à biblioteca de referências, que também foram arquivados e catalogados. Alguns trabalhos inicialmente selecionados acabaram não sendo utilizados; por isso, dessas 65 referências, foram citadas na pesquisa 54, entre artigos de periódicos, livros, normas técnicas, 
dissertações, anais de eventos, atos administrativos, artigos apresentados em congressos e documentos de acesso em meio eletrônico.

\section{Etapa II: o estudo de caso}

De acordo com Yin (2001, p. 32-33), "[...] a investigação de estudo de caso enfrenta uma situação tecnicamente única em que haverá muito mais variáveis de interesse do que pontos de dados, e, como resultado, baseia-se em várias fontes de evidências [...]". Esta pesquisa se enquadra nesse conceito, pois se baseia em várias fontes de evidências observadas nas empresas: projetos, memoriais descritivos, formulários, relatórios, e-mails, contratos, entrevistas, etc. Prodanov e Freitas (2013) também alegam que a convergência de resultados provenientes de fontes distintas oferece um excelente grau de confiabilidade ao estudo.

\section{Caracterização das empresas}

O estudo de caso foi feito em duas construtoras da cidade de Juiz de Fora, MG, certificadas no nível A do SiAC - PBQP-H. Ambas atuam no subsetor de edificações, executando empreendimentos residenciais, com foco no programa Minha Casa Minha Vida (MCMV), tendo como principal órgão financiador a Caixa Econômica Federal. O Quadro 2 apresenta, de maneira sintética, a caracterização das empresas.

Ambas as empresas executam, atualmente, empreendimentos para o programa MCMV, com sistema construtivo principal em alvenaria estrutural, de blocos cerâmicos ou de concreto. A empresa A também executa empreendimentos de incorporação, com recursos próprios ou por meio de financiamento imobiliário.

A NBR 15575 está sendo implantada nas duas empresas, tendo a empresa A iniciado em dezembro de 2015 e a empresa B iniciado em julho de 2017. As empresas contrataram a mesma consultoria para orientações e elaboração de procedimentos e formulários de acompanhamento. A consultoria enviou dois consultores para a realização dos trabalhos em cada empresa.

$\mathrm{Na}$ empresa A, a direção e os setores comercial e de planejamento acompanharam o processo de implantação; o arquiteto terceirizado, que trabalha em regime de parceria com a construtora e é responsável pelos projetos legal e executivo de arquitetura, também participou das discussões. Atualmente, foi designado um engenheiro civil, contratado posteriormente ao início da implantação, para coordenar as questões relativas à NBR 15575, sendo de sua responsabilidade arquivar as evidências de cumprimento.

$\mathrm{Na}$ empresa B, o processo de implantação foi acompanhado de perto pelo arquiteto coordenador do setor de projetos, que também é o principal responsável pelo armazenamento das evidências de cumprimento relativas à adequação de projetos e ensaios dos empreendimentos. O setor de compras é o encarregado de coletar e armazenar laudos de ensaios dos materiais.

Os autores acompanharam a implantação nas empresas desde o início; na empresa A, a coleta de dados para a pesquisa se estendeu até março de 2019; na empresa B, até setembro de 2018. Os autores participaram das reuniões entre os consultores da norma e os membros das empresas; revisaram, com orientação dos consultores, os procedimentos do SGQ que tinham interface direta com o atendimento à NBR 15575 (especialmente das áreas comercial e de projetos); adaptaram, conforme necessidade das empresas, os formulários correlatos a esses procedimentos; por fim, coletaram os dados que são o resultado de todo esse processo. Essa coleta envolveu entrevistas com os responsáveis pelo acompanhamento da implantação da NBR 15575 e acesso aos arquivos relacionados ao tema, armazenados nos servidores das construtoras. Esse processo de acompanhamento foi semelhante em ambas as empresas, e suas etapas estão esquematizadas na Figura 1.

$\mathrm{Na}$ empresa A, foram analisados quatro empreendimentos; na empresa B, foram analisados dois empreendimentos.

\section{Resultados e discussões}

\section{Empresa A}

Os arquivos estão sendo armazenados em meio eletrônico, em diretório específico no computador do setor de planejamento, onde estão os projetos de cada empreendimento. A empresa optou por essa abordagem pela facilidade de recuperação das informações, pela possibilidade de se imprimir e criar cópias físicas dos 
documentos caso necessário e pela garantia de preservação dos dados por meio de backups. A empresa não possui qualquer tipo de gestão eletrônica de documentos.

A empresa já possuía uma estrutura de organização dos projetos de cada obra, que foi adaptada para receber as evidências de cumprimento da norma. Dentro da pasta de projetos de cada empreendimento, foi criada uma pasta chamada "NBR 15575", na qual são arquivadas todas as informações relativas à implantação da norma naquela obra.

As subpastas da pasta "NBR 15575" não têm estrutura definida, e variam entre as obras conforme necessidade. Há obras com apenas uma subpasta a obras com mais de quarenta, o que demonstra a ausência de padronização. O conteúdo das subpastas abrange: atas de reuniões, relatórios de consultorias, resultados de ensaios das obras, laudos de ensaios de materiais e perfil de desempenho da edificação (PDE), conforme esquematizado no Quadro 3.

Além disso, a empresa tentou sistematizar a verificação de atendimento à norma por meio de preenchimento de checklists. Na obra piloto da aplicação da NBR 15575 na empresa, foi adotado o formulário da qualidade destinado a esse fim, o checklist de verificação, para cada especialidade técnica (arquitetura, incêndio, hidrossanitário, etc.). Nas demais obras, por iniciativa do engenheiro, tentou-se aplicar o checklist do Inovacon-CE, pois, além da análise de projeto, ele cobre também evidências de ensaios, inspeções e simulações.

\section{Quadro 2 - Caracterização das empresas}

\begin{tabular}{|c|c|c|}
\hline Empresa: & $\mathbf{A}$ & $\mathbf{B}$ \\
\hline Ano de fundação & 1968 & 2008 \\
\hline Perfil de atuação & Construtora e incorporadora familiar. & $\begin{array}{l}\text { Opera principalmente como } \\
\text { incorporadora, terceirizando total } \\
\text { ou parcialmente a construção de } \\
\text { seus empreendimentos. }\end{array}$ \\
\hline Região de atuação & $\begin{array}{l}\text { Várias regiões do país, notadamente em } \\
\text { Minas Gerais, Rio de Janeiro, Espírito } \\
\text { Santo. }\end{array}$ & $\begin{array}{l}\text { Atua principalmente em Juiz de } \\
\text { Fora, mas também possui obras em } \\
\text { outras cidades de MG, além de ter } \\
\text { planos de se expandir para todo o } \\
\text { país em longo prazo. }\end{array}$ \\
\hline $\begin{array}{l}\text { Tipos de } \\
\text { empreendimentos } \\
\text { residenciais }\end{array}$ & $\begin{array}{l}\text { Adota, para obras do MCMV faixa } 1,5, \\
\text { configuração de blocos de } 4 \text { ou } 5 \\
\text { pavimentos, com } 4 \text { unidades por andar, } \\
\text { buscando maximizar a quantidade de } \\
\text { blocos no terreno (de } 6 \text { a } 12 \text {, usualmente). } \\
\text { Em obras de incorporação ou do MCMV } \\
\text { faixa } 3 \text {, opta por configuração de } 1 \text { ou } 2 \\
\text { blocos apenas, de até } 10 \text { pavimentos. }\end{array}$ & $\begin{array}{l}\text { Para obras do MCMV faixas } 1,5 \text { ou } \\
2 \text {, prefere executar blocos mais } \\
\text { robustos, de } 10 \text { pavimentos, com } \\
10 \text { unidades por andar, podendo, } \\
\text { nesse caso, ter empreendimentos } \\
\text { desde apenas } 2 \text { blocos implantados } \\
\text { até empreendimentos com } 10 \\
\text { blocos. }\end{array}$ \\
\hline
\end{tabular}

Figura 1 - Etapas da coleta de dados nas empresas A e B

\begin{tabular}{|c|c|c|c|}
\hline Etapa 1 & Etapa 2 & Etapa 3 & Etapa 4 \\
\hline 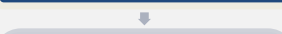 & 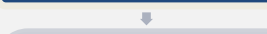 & $=$ & 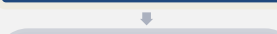 \\
\hline $\begin{array}{l}\text { Participação nas } \\
\text { reuniões entre os } \\
\text { consultores da norma } \\
\text { e os membros das } \\
\text { empresas }\end{array}$ & $\begin{array}{l}\text { Revisão dos } \\
\text { procedimentos do } \\
\text { SGQ com interface } \\
\text { direta com a NBR } \\
15575 \\
\text { (especialmente das } \\
\text { áreas comercial e de } \\
\text { projetos) }\end{array}$ & $\begin{array}{l}\text { Adaptação de } \\
\text { formulários correlatos } \\
\text { aos procedimentos }\end{array}$ & $\begin{array}{l}\text { Coleta de dados } \\
\text { - Entrevistas com os } \\
\text { responsáveis pelo } \\
\text { acompanhamento } \\
\text { da implantação da } \\
\text { NBR } 15575 \\
\text { - Acesso aos arquivos } \\
\text { relacionados ao } \\
\text { tema, armazenados } \\
\text { nos servidores das } \\
\text { construtoras }\end{array}$ \\
\hline
\end{tabular}


Quadro 3 - Conteúdo das pastas de NBR 15575 na empresa A

\begin{tabular}{|c|c|c|c|c|}
\hline Obra & Ensaios de campo & Análise de projeto & $\begin{array}{l}\text { Laudos de } \\
\text { fornecedo- } \\
\text { res de } \\
\text { materiais }\end{array}$ & Documentação extra \\
\hline A 1 & $\begin{array}{l}\text { Níveis de ruído ambiente } \\
\left(\mathrm{L}_{\mathrm{ra}}\right)\end{array}$ & $\begin{array}{l}\text { Relatório técnico } \\
\text { com sugestões de } \\
\text { mudanças nos } \\
\text { materiais e ajustes } \\
\text { em alguns métodos } \\
\text { construtivos }\end{array}$ & $---\mathrm{X}---$ & $---X---$ \\
\hline A2 & $\begin{array}{l}\text { Níveis de ruído ambiente } \\
\left(\mathrm{L}_{\mathrm{ra}}\right) \\
\text { Desempenho acústico do } \\
\text { ruído de impacto da } \\
\text { vedação horizontal (piso) }\end{array}$ & $\begin{array}{l}\text { Laudo de análise do } \\
\text { projeto de alvenaria } \\
\text { estrutural } \\
\text { Checklists de } \\
\text { verificação de } \\
\text { projetos da } \\
\text { Qualidade } \\
\text { Checklist do } \\
\text { Inovacon-CE }\end{array}$ & $\begin{array}{l}\text { Argamassa } \\
\text { colante } \\
\text { Esquadria de } \\
\text { alumínio } \\
\text { Porta de } \\
\text { madeira } \\
\text { Piso } \\
\text { cerâmico }\end{array}$ & $\begin{array}{l}\text { Atas de reunião } \\
\text { PDE } \\
\text { Procedimento para execução de } \\
\text { fachadas (consultoria específica) } \\
\text { Procedimento de preparação da área } \\
\text { para ensaios de impacto (consultoria } \\
\text { específica) } \\
\text { Procedimento para execução de } \\
\text { ensaios de impacto de corpo duro em } \\
\text { pisos e paredes e de corpo mole em } \\
\text { paredes (consultoria específica) } \\
\text { Procedimento para especificações a } \\
\text { serem solicitadas aos fornecedores } \\
\text { de materiais (consultoria específica) }\end{array}$ \\
\hline A3 & $\begin{array}{l}\text { Níveis de ruído ambiente } \\
\left(\mathrm{L}_{\mathrm{ra}}\right) \\
\text { Isolamento do ruído de } \\
\text { sistemas de vedações } \\
\text { verticais internas (paredes) } \\
\left(\mathrm{D}_{\mathrm{nT}, \mathrm{w}}\right) \\
\text { Isolamento do ruído de } \\
\text { impacto em sistema de piso } \\
\left(\mathrm{L}_{\mathrm{nT}, \mathrm{w}}^{\prime}\right) \\
\text { Isolamento do ruído aéreo } \\
\text { de sistemas de vedações } \\
\text { externas }\left(\mathrm{D}_{2 \mathrm{~m}, \mathrm{nT}, \mathrm{w}}\right) \\
\text { Isolamento de ruído aéreo } \\
\text { de sistemas de piso }\left(\mathrm{D}_{\mathrm{nT}, \mathrm{w}}\right) \\
\end{array}$ & $\begin{array}{l}\text { Checklist do } \\
\text { Inovacon-CE } \\
\text { (parcialmente } \\
\text { preenchido) }\end{array}$ & $\begin{array}{l}\text { Argamassa } \\
\text { colante } \\
\text { Esquadria de } \\
\text { alumínio } \\
\text { Porta de } \\
\text { madeira } \\
\text { Piso } \\
\text { cerâmico }\end{array}$ & $\begin{array}{l}\text { Atas de reunião } \\
\text { Procedimento de impermeabilização } \\
\text { de áreas frias } \\
\text { Procedimento de preparação da área } \\
\text { para ensaios de impacto } \\
\text { Procedimento para execução de } \\
\text { ensaios de impacto de corpo duro em } \\
\text { pisos e paredes e de corpo mole em } \\
\text { paredes } \\
\text { Procedimento para especificações a } \\
\text { serem solicitadas aos fornecedores } \\
\text { de materiais }\end{array}$ \\
\hline A4 & $\begin{array}{l}\text { Níveis de ruído ambiente } \\
\left(\mathrm{L}_{\mathrm{ra}}\right)\end{array}$ & $\begin{array}{l}\text { Checklist do } \\
\text { Inovacon-CE } \\
\text { (ainda em branco) }\end{array}$ & $\begin{array}{l}\text { Argamassa } \\
\text { colante } \\
\text { Porta de } \\
\text { madeira } \\
\end{array}$ & $---\mathrm{X}---$ \\
\hline
\end{tabular}

\section{Empresa B}

Os arquivos também estão sendo armazenados em meio eletrônico. Os projetos das obras analisadas, já com as alterações decorrentes da implantação da norma, estão arquivados em diretório específico do servidor, separados por empreendimento. Os laudos de ensaios de campo das obras estão sendo arquivados na pasta "Norma de Desempenho", dentro do diretório da qualidade no servidor da empresa (esses laudos também estão arquivados como anexos nos e-mails recebidos pelos laboratórios. A organização neste caso se dá somente por remetente e assunto). A empresa B também não possui qualquer tipo de gestão eletrônica de documentos.

Como na empresa A, também foram criados formulários para o SGQ da empresa de forma a atender aos requisitos da norma. Esses formulários abrangem, principalmente, as áreas comerciais (para análise de risco de terrenos) e de projetos (análise crítica e verificação).

A consultoria forneceu uma tabela com todos os ensaios requeridos pela norma para orientar a empresa. Dos 65 que seriam necessários para o total cumprimento, a construtora optou por começar com um conjunto de 
24, definidos pela consultoria como essenciais e com maior potencial de problemas. Desses 24, já foram realizados 12 e há perspectivas da contratação de mais 6 em breve, conforme esquematizado no Quadro 4.

Os ensaios realizados em cada obra analisada e a documentação armazenada estão listados no Quadro 5.

\section{Quadro 4 - Ensaios feitos pela empresa B}

\begin{tabular}{|c|c|c|c|c|c|}
\hline Sistema & Tema & Ensaios necessários & $\begin{array}{c}\text { Recomen- } \\
\text { dado }\end{array}$ & $\begin{array}{c}\text { Já } \\
\text { feito }\end{array}$ & $\begin{array}{c}\text { Em } \\
\text { breve }\end{array}$ \\
\hline Cobertura & \begin{tabular}{|l|} 
Durabilidade e \\
manutenibilidade
\end{tabular} & Estabilidade da cor da telha & & $\mathrm{x}$ & \\
\hline Cobertura & Estanqueidade & $\begin{array}{l}\text { Estanqueidade à água do sistema de cobertura } \\
\text { e impermeabilidade de telhas }\end{array}$ & & & $\mathrm{x}$ \\
\hline Cobertura & Segurança estrutural & $\begin{array}{l}\text { Resistência de suportes das garras de fixação } \\
\text { ou apoio e de peças fixadas no forro }\end{array}$ & $\mathrm{x}$ & & \\
\hline Geral & $\begin{array}{l}\text { Desempenho } \\
\text { acústico }\end{array}$ & Medição de ruído no local e entorno & $\mathrm{x}$ & & \\
\hline Geral & $\begin{array}{l}\text { Desempenho } \\
\text { lumínico }\end{array}$ & $\begin{array}{l}\text { Iluminação natural (simulação e medição in } \\
\text { loco fator de luz diurna) }\end{array}$ & $\mathrm{x}$ & & $\mathrm{x}$ \\
\hline Geral & $\begin{array}{l}\text { Desempenho } \\
\text { lumínico }\end{array}$ & $\begin{array}{l}\text { Iluminação artificial (Simulação e medição in } \\
\text { loco) }\end{array}$ & & & $\mathrm{x}$ \\
\hline Geral & Desempenho térmico & Desempenho térmico por software & $\mathrm{x}$ & & $\mathrm{x}$ \\
\hline Piso & $\begin{array}{l}\text { Desempenho } \\
\text { acústico }\end{array}$ & $\begin{array}{l}\text { Isolação acústica entre ambientes - ruído } \\
\text { aéreo entre pisos }\end{array}$ & $\mathrm{x}$ & $\mathrm{x}$ & \\
\hline Piso & $\begin{array}{l}\text { Desempenho } \\
\text { acústico }\end{array}$ & $\begin{array}{l}\text { Níveis de ruídos permitidos na habitação - } \\
\text { ruídos de impacto nos pisos }\end{array}$ & $\mathrm{x}$ & $\mathrm{x}$ & \\
\hline Piso & Estanqueidade & $\begin{array}{l}\text { Estanqueidade de pisos áreas molhadas e } \\
\text { molháveis }\end{array}$ & $\mathrm{x}$ & & \\
\hline Piso & Segurança estrutural & Resistência a impacto de corpo mole & $\mathrm{x}$ & & \\
\hline Piso & Segurança estrutural & Resistência a impacto de corpo duro & $\mathrm{x}$ & & \\
\hline Piso & Segurança estrutural & Cargas verticais concentradas & $\mathrm{x}$ & & \\
\hline Vedações & $\begin{array}{l}\text { Desempenho } \\
\text { acústico }\end{array}$ & $\begin{array}{l}\text { Isolação acústica entre ambientes - ruído } \\
\text { aéreo entre paredes internas }\end{array}$ & $\mathrm{x}$ & $\mathrm{x}$ & \\
\hline Vedações & $\begin{array}{l}\text { Desempenho } \\
\text { acústico }\end{array}$ & $\begin{array}{l}\text { Isolação acústica das paredes externas } \\
\text { (fachadas) }\end{array}$ & $\mathrm{x}$ & $\mathrm{x}$ & \\
\hline Vedações & $\begin{array}{l}\text { Desempenho } \\
\text { acústico }\end{array}$ & $\begin{array}{l}\text { Isolação acústica entre vedação da unidade } \\
\text { habitacional e áreas comuns de permanência }\end{array}$ & $\mathrm{x}$ & & \\
\hline Vedações & $\begin{array}{l}\text { Desempenho } \\
\text { acústico }\end{array}$ & $\begin{array}{l}\text { Isolação acústica entre vedação da unidade } \\
\text { habitacional e áreas comuns de trânsito } \\
\text { eventual }\end{array}$ & $\mathrm{x}$ & & \\
\hline Vedações & $\begin{array}{l}\text { Desempenho } \\
\text { acústico }\end{array}$ & $\begin{array}{l}\text { Medição acústica de paredes e portas } \\
\text { separados pelo hall }\end{array}$ & $\mathrm{x}$ & & \\
\hline Vedações & \begin{tabular}{|l|} 
Durabilidade e \\
manutenibilidade
\end{tabular} & $\begin{array}{l}\text { Verificação à exposição de calor e choque } \\
\text { térmico }\end{array}$ & $\mathrm{x}$ & $\mathrm{x}$ & \\
\hline Vedações & Estanqueidade & $\begin{array}{l}\text { Permeabilidade de água - vedações internas e } \\
\text { externas }\end{array}$ & $\mathrm{x}$ & $\mathrm{x}$ & \\
\hline Vedações & Segurança estrutural & $\begin{array}{l}\text { Resistência de vedações a solicitação de peças } \\
\text { suspensas }\end{array}$ & $\mathrm{x}$ & $\mathrm{x}$ & \\
\hline Vedações & Segurança estrutural & $\begin{array}{l}\text { Ações transmitidas por portas - fechamento } \\
\text { brusco }\end{array}$ & $\mathrm{x}$ & $\mathrm{x}$ & \\
\hline Vedações & Segurança estrutural & $\begin{array}{l}\text { Ações transmitidas por portas - impacto de } \\
\text { corpo mole }\end{array}$ & $\mathrm{x}$ & $\mathrm{x}$ & \\
\hline Vedações & Segurança estrutural & Esforço horizontal e impacto em guarda-corpo & $\mathrm{x}$ & & $\mathrm{x}$ \\
\hline Vedações & Segurança estrutural & $\begin{array}{l}\text { Cargas de ocupação incidentes em guarda- } \\
\text { corpos e parapeitos } \\
\text { (carga horizontal, carga vertical, impacto de } \\
\text { corpo mole) }\end{array}$ & $\mathrm{x}$ & & $\mathrm{x}$ \\
\hline Vedações & Segurança estrutural & Resistência a impacto de corpo duro & $\mathrm{x}$ & $\mathrm{x}$ & \\
\hline Vedações & Segurança Estrutural & Resistência a impacto de corpo mole & $\mathrm{x}$ & $\mathrm{x}$ & \\
\hline
\end{tabular}

Fonte: baseado em informações coletadas na empresa B. 
Quadro 5 - Ensaios realizados e documentos arquivados da empresa B

\begin{tabular}{|c|c|c|c|c|c|}
\hline Obra & Ensaio & $\begin{array}{c}\text { Análise de } \\
\text { projeto }\end{array}$ & $\begin{array}{c}\text { Laudos de } \\
\text { fornecedores } \\
\text { de materiais }\end{array}$ & $\begin{array}{c}\text { Ensaios } \\
\text { próprios de } \\
\text { materiais }\end{array}$ & $\begin{array}{c}\text { Documenta- } \\
\text { ção extra }\end{array}$ \\
\hline 1 & $\begin{array}{l}\text { Ruído de impacto em piso entre } \\
\text { unidades } \\
\text { Ruído aéreo em piso entre unidades } \\
\text { Ruído aéreo entre paredes internas } \\
\text { Ruído aéreo de fachada }\end{array}$ & $\begin{array}{l}\text { Checklists de } \\
\text { verificação } \\
\text { de projetos } \\
\text { da qualidade }\end{array}$ & $\begin{array}{l}\text { Esquadria de } \\
\text { alumínio } \\
\text { Piso } \\
\text { cerâmico }\end{array}$ & ---X--- & PDE \\
\hline 2 & $\begin{array}{l}\text { Determinação da resistência dos } \\
\text { SVVIE peças suspensas } \\
\text { Verificação da resistência à impactos } \\
\text { de corpo duro } \\
\text { Impactos de corpo mole (vedação } \\
\text { interna, vedação externa - face interna, } \\
\text { vedação externa - face externa) } \\
\text { Verificação estanqueidade à água de } \\
\text { SVVE } \\
\text { Verificação SVVE exposto à ação de } \\
\text { calor e choque térmico } \\
\text { Verificação da resistência ao impacto } \\
\text { em telhados } \\
\text { Ruído de impacto em piso entre } \\
\text { unidades } \\
\text { Ruído aéreo em piso entre unidades } \\
\text { Ruído aéreo entre paredes internas } \\
\text { Ruído aéreo de fachada }\end{array}$ & $\begin{array}{l}\text { Não } \\
\text { aplicáveis, } \\
\text { pois } \\
\text { implantação } \\
\text { da NBR foi } \\
\text { posterior à } \\
\text { etapa de } \\
\text { execução de } \\
\text { projetos }\end{array}$ & $\begin{array}{l}\text { Esquadria de } \\
\text { alumínio } \\
\text { Piso } \\
\text { cerâmico }\end{array}$ & $\begin{array}{l}\text { Ensaios de } \\
\text { fechamento } \\
\text { brusco em } \\
\text { portas } \\
\text { Ensaios de } \\
\text { choque de } \\
\text { abalo em } \\
\text { portas }\end{array}$ & ---X--- \\
\hline
\end{tabular}

Fonte: baseado em informações coletadas na empresa $B$.

A listagem de ensaios estava armazenada na pasta "Norma de Desempenho" no servidor, no qual ficavam também os documentos de caráter mais generalista, aplicáveis a todas as obras, que eram todos os formulários e documentos fornecidos pela consultoria da norma, tais como: diagnóstico inicial da empresa, modelo de PDE, planilha de análise de entorno/planejamento preliminar de riscos, planilha para controle de especificações de acabamentos (com requisitos a serem atendidos pelos materiais, tais como cerâmicas e esquadrias), checklist para contratação e recebimento de projetos das especialidades técnicas e procedimento com orientações para contratação de projetistas.

A empresa B não sentiu necessidade de adotar outro checklist que não o fornecido pela consultoria da norma. O preenchimento dos formulários estava a cargo do arquiteto que coordena o setor de projetos da empresa.

\section{Considerações sobre a informação documentada das empresas}

Usando as exigências do Regimento SiAC como guia, pode-se analisar a geração e o controle de informação documentada sobre a NBR 15575 conforme os seguintes temas:

(a) criação e atualização;

(b) distribuição, acesso, recuperação e uso;

(c) armazenamento e preservação, incluindo preservação de legibilidade;

(d) controle de alterações; e

(e) retenção e disposição.

\section{Criação e atualização}

Os checklists do Inovacon-CE, que começaram a ser usados na empresa A, são uma tentativa incipiente de verificação de cumprimento da norma, mas não estão sendo usados em sua plenitude, nem divulgados nos 
demais setores. O próprio engenheiro entrevistado disse que tem tido dificuldade em adotá-lo por achá-lo muito extenso e trabalhoso.

Em ambas as empresas, a criação de registros de cumprimento da norma ainda está muito centralizada em um só funcionário (na empresa A, no engenheiro civil do setor de planejamento; na empresa B, no arquiteto coordenador do setor de projetos). A centralização do processo em uma só pessoa envolve riscos óbvios: gargalo em caso de crescimento da empresa; atraso ou até mesmo paralisia do processo em caso de ausência do funcionário por qualquer motivo (doença, férias, demissão, realocação, etc.).

Os laudos de materiais variam muito de empresa para empresa e de obra para obra. Dentro da empresa A, por exemplo, há obras já armazenando laudos de argamassa colante, enquanto outras ainda não. É necessário definir uma lista de materiais que deverão ter sempre laudos de ensaios arquivados; a adoção de um checklist pode solucionar essa questão.

As empresas ainda não definiram um plano de controle tecnológico que abranja todos os ensaios requeridos pela NBR 15575 e que estejam planejados ou sendo realizados nas obras.

A empresa B se beneficiou por ter começado a implantação muito tempo depois da empresa A, com a mesma consultoria, pois o material de orientação já havia sido testado e aperfeiçoado em outras empresas, inclusive fora de Juiz de Fora. Isso fica evidente ao se analisar o formato e a complexidade da documentação fornecida pelos consultores. Talvez seja interessante a empresa A solicitar um upgrade dessa documentação para se manter atualizada.

\section{Distribuição, acesso, recuperação e uso}

Não foram definidas regras nas empresas para distribuição das informações, restrição de acesso, forma de indexação (recuperação) e necessidade de uso por cada setor.

Alguns documentos da empresa B estão também arquivados anexados a e-mails. Deve-se evitar essa forma de armazenamento, pois ela dificulta a recuperação das informações por vários motivos:

(a) o banco de dados pode se perder com o tempo, caso não haja backups e/ou em caso de atualização de hardware;

(b) pode ser difícil recuperar a informação de uma obra específica caso um e-mail de um laboratório de ensaios, por exemplo, contenha laudos de mais de uma obra diferente; e

(c) o e-mail fica associado à conta do usuário, o que pode ser um problema em caso de demissão ou troca de função. Também dificulta o acesso por outras pessoas que não sejam o usuário daquela conta.

\section{Armazenamento e preservação, incluindo preservação de legibilidade}

As atitudes no sentido de arquivar corretamente as informações estão sendo tomadas unicamente por iniciativa dos funcionários, mas não há uma formalização por parte da empresa quanto ao controle desses registros. Essa situação tem o risco potencial de, em caso de mudança de funcionário do setor, alterar-se completamente a forma de arquivamento ou até mesmo deixarem de ser arquivadas informações importantes.

Uma estrutura padronizada de pastas eletrônicas permitiria avaliar, apenas com uma rápida auditoria comparativa, se todos os registros estão sendo arquivados. A atual estrutura não padronizada das empresas dificulta muito essa verificação.

\section{Controle de alterações}

Não foram definidas regras para controle de versões dos documentos, especialmente oriundos de terceiros: laudos de ensaios de campo, propostas comerciais de ensaios e consultorias, laudos de ensaios de materiais, etc. Há risco potencial de uso de documentos obsoletos.

Não há cuidados especiais de proteção contra alterações, ainda que não intencionais. O acesso aos arquivos se dá mediante login e senha no servidor; contudo, mais de uma pessoa possui essa prerrogativa na rede, em ambas as empresas. 


\section{Retenção e disposição}

As empresas ainda não definiram por quanto tempo vão arquivar os registros, que começam agora a ser criados e poderão ser exigidos daqui a muitos anos. As diretrizes a serem propostas nesta pesquisa visam justamente suprir, entre outras, essa lacuna.

\section{Proposição de diretrizes}

Com base nas considerações sobre as empresas, são sugeridas diretrizes para diminuir as dificuldades no controle de informação documentada gerada pela NBR 15575. Essas diretrizes são aplicáveis a empresas que não possuem gestão eletrônica de documentos e são propostas conforme os itens exigidos pelo SiAC para controle de informação documentada, conforme as seguintes seções, apresentadas no Quadro 6:

(a) criação e atualização;

(b) distribuição, acesso, recuperação e uso;

(c) armazenamento e preservação, incluindo preservação de legibilidade;

(d) controle de alterações; e

(e) retenção e disposição.

Quanto ao tempo de retenção, sugere-se adotar os prazos de VUP da NBR 15575. Esses prazos foram aplicados ao checklist de Costella (2018) e podem ser encontrados em Lazzarini (2019). Em função da limitação de espaço, não é possível a sua reprodução neste artigo, sendo uma representação parcial, a título ilustrativo, mostrada no Quadro 7.

Optou-se por esse checklist, dentre os demais apresentados, por entender-se que era o mais enxuto e objetivo, o que agilizaria o preenchimento. Além disso, ele prioriza o método de avaliação de análise de projeto, o que torna o cumprimento da norma mais fácil para as empresas.

Na elaboração desse novo checklist, com definição de prazos de retenção, foram adotadas as seguintes premissas:

(a) utilizou-se a VUP mínima definida pela norma para todos os itens;

(b) para critérios que impactavam a segurança do usuário (estrutural, no uso e operação e contra incêndio), adotou-se a VUP maior dentre os três, de 50 anos;

(c) para critérios que se aplicavam tanto a sistemas de vedação vertical interna (SVVI) quanto a sistemas de vedação vertical externa (SVVE), adotou-se o mais rigoroso, do sistema externo, de 40 anos; e

(d) na Parte 1 -Requisitos gerais: para estanqueidade, foi adotada a VUP de pisos; tanto para desempenho lumínico quanto para desempenho em saúde, higiene e qualidade do ar, foi adotada a VUP de esquadrias externas; para durabilidade, foi adotada a VUP de estruturas; para funcionalidade e acessibilidade, foi adotada a VUP de estrutura, por conter declarações em projetos correlatos; para conforto tátil e antropodinâmico, foi adotada a VUP de hidrossanitária, pois o item engloba também metais sanitários e a VUP, nesse caso, é mais rigorosa que a de esquadrias.

\section{Considerações finais}

As construtoras finalmente começaram a implantar a NBR 15575, depois de um período de inércia após a sua publicação. Esse movimento tende a se acelerar devido à recente exigência de cumprimento da norma por parte do SiAC PBQP-H. De maneira a auxiliar as empresas que iniciam esse processo, este trabalho apresentou diretrizes para controle da informação documentada gerada pela implantação da norma, incluindo-se aí o tempo de retenção dessa informação. O desenvolvimento baseou-se em um estudo exploratório sobre a organização da informação em empresas construtoras de maneira a atender aos requisitos normativos da NBR 15575.

O estudo de caso permitiu levantar a documentação gerada pelas empresas na implantação da referida norma. Constatou-se que essa documentação envolvia laudos de ensaios de campo nos empreendimentos, laudos de ensaios de materiais, análises de projeto (internas ou externas), perfil de desempenho da edificação, projetos com informações exigidas pela norma, checklist de verificação, atas de reunião e procedimentos. Além disso, permitiu também identificar as formas de controle dessa documentação adotadas 
pelas empresas. Constatou-se que o armazenamento se dava em meio eletrônico, em pastas dedicadas à norma nos computadores de projetos, mas sem uma estrutura definida.

Nesse sentido, a contribuição deste trabalho está nas diretrizes elaboradas para o controle da informação documentada e gerada na empresa pela implantação da NBR 15575. Essas diretrizes são aplicáveis às empresas que ainda não possuem gestão eletrônica de documentos, e deverá, portanto, ser adaptada às empresas que já fazem uso dessa tecnologia.

\section{Quadro 6 - Diretrizes propostas conforme os itens exigidos pelo SiAC}

\begin{tabular}{|c|c|}
\hline Requisito SiAC & Diretriz proposta \\
\hline \multirow{6}{*}{$\begin{array}{l}\text { Criação e } \\
\text { atualização }\end{array}$} & $\begin{array}{l}\text { Definir, em procedimento, os responsáveis pela criação e pela atualização de toda } \\
\text { evidência de cumprimento da NBR } 15575 \text {. }\end{array}$ \\
\hline & $\begin{array}{l}\text { A tarefa de cuidar da informação documentada não deve ser responsabilidade de } \\
\text { somente uma pessoa, mas compartilhada com pelo menos mais um(a) funcionário(a), } \\
\text { para substitui-lo(a) em caso de ausência (férias, afastamento por saúde, etc.), demissão } \\
\text { ou troca de função. }\end{array}$ \\
\hline & $\begin{array}{l}\text { Adotar um checklist de verificação de cumprimento, que seja de fácil compreensão e } \\
\text { preenchimento, e que facilite o acompanhamento da implantação da norma em cada } \\
\text { empreendimento. }\end{array}$ \\
\hline & $\begin{array}{l}\text { Definir uma lista de laudos de materiais que sejam sempre exigidos dos fornecedores, } \\
\text { preferencialmente pelo setor de compras/aquisição. Convém também que o } \\
\text { arquivamento desses documentos não seja independente dos demais registros de } \\
\text { cumprimento da norma, para facilitar a conferência na hora do preenchimento do } \\
\text { checklist. }\end{array}$ \\
\hline & $\begin{array}{l}\text { O plano de controle tecnológico pode ser uma ferramenta útil como base de controle } \\
\text { dos ensaios que foram realizados. }\end{array}$ \\
\hline & $\begin{array}{l}\text { A empresa manter-se atualizada nas alterações da norma e no que vem sendo feito por } \\
\text { outras empresas para cumpri-la. A participação, pelo menos anual, de funcionários em } \\
\text { congressos, palestras, cursos e seminários pode ser útil nesse sentido. Uma proposta de } \\
\text { revisão das soluções implantadas inicialmente pela empresa de consultoria da norma } \\
\text { também pode ser adequada para esse fim. }\end{array}$ \\
\hline \multirow{2}{*}{$\begin{array}{l}\text { Distribuição, } \\
\text { acesso, recuperação } \\
\text { e uso }\end{array}$} & $\begin{array}{l}\text { Definir regras para distribuição e uso das informações (quem vai acompanhar o } \\
\text { processo de implantação e poderá se valer do conteúdo da informação documentada), } \\
\text { restrição de acesso (como essas pessoas - e somente elas - terão acesso às } \\
\text { informações) e forma de indexação (regras para organização, tais como data, número, } \\
\text { versão, etc.). }\end{array}$ \\
\hline & $\begin{array}{l}\text { Evitar arquivar a informação documentada somente em e-mails. Essa forma de arquivo } \\
\text { deverá ser usada somente como redundância da principal, em pastas em computadores } \\
\text { destinadas a esse fim. }\end{array}$ \\
\hline \multirow{2}{*}{$\begin{array}{l}\text { Armazenamento e } \\
\text { preservação, } \\
\text { incluindo } \\
\text { preservação de } \\
\text { legibilidade }\end{array}$} & $\begin{array}{l}\text { Formalizar regras para armazenamento da informação documentada, de forma que o } \\
\text { procedimento possa ser aplicado e replicado independentemente de iniciativas } \\
\text { individuais ou de janelas temporais, a fim de criar padronização ao longo do tempo. }\end{array}$ \\
\hline & $\begin{array}{l}\text { Definir uma estrutura de pastas eletrônicas que se repita em todos os } \\
\text { empreendimentos, de forma a facilitar a recuperação de informações e avaliar se todos } \\
\text { os registros estão sendo arquivados - e se estão arquivados corretamente. }\end{array}$ \\
\hline \multirow[b]{2}{*}{$\begin{array}{l}\text { Controle de } \\
\text { alterações }\end{array}$} & Controle de alterações \\
\hline & $\begin{array}{l}\text { Definir regras para controle de versões dos documentos, especialmente oriundos de } \\
\text { terceiros, para evitar uso acidental de documentos obsoletos. }\end{array}$ \\
\hline $\begin{array}{l}\text { Retenção e } \\
\text { disposição }\end{array}$ & $\begin{array}{l}\text { Definir tempo de retenção e disposição da informação documentada. Recomenda-se } \\
\text { que a disposição seja a total destruição da informação (por exemplo, por meio de } \\
\text { fragmentação ou incineração), por se tratar de conteúdo sensível à organização. }\end{array}$ \\
\hline
\end{tabular}


Quadro 7 - Tempo de retenção da informação documentada

\begin{tabular}{|c|c|c|c|c|c|c|c|}
\hline Parte &  & Critério & Verificação &  & 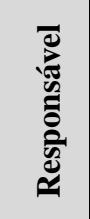 &  & 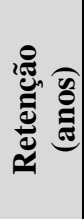 \\
\hline 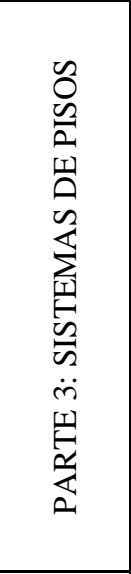 & 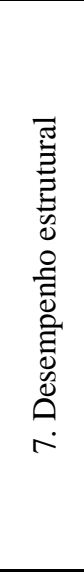 & 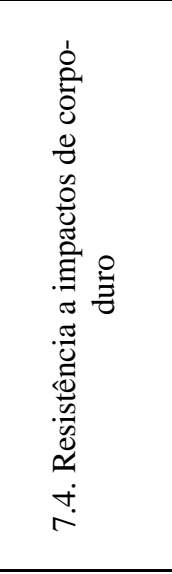 & $\begin{array}{l}\text { O sistema de pisos deve atender a Tabela } 1 \text { da } \\
\text { NBR 15575-3. } \\
\text { Para energia de impacto de corpo duro de 5J: Não } \\
\text { ocorrência de ruptura total da camada de } \\
\text { acabamento, permitidas falhas superficiais, como } \\
\text { mossas, lascamentos, fissuras e desagregações. } \\
\text { Para energia de impacto de corpo duro de } 30 \mathrm{~J} \text { : } \\
\text { Não ocorrência de ruína e transpassamento, } \\
\text { permitidas falhas superficiais como mossas, } \\
\text { fissuras lascamentos e desagregações. } \\
\text { O fornecedor deve disponibilizar o laudo de } \\
\text { ensaio do revestimento (camada de acabamento), } \\
\text { seguindo as premissas do Anexo A da NBR } \\
\text { 15575-2. } \\
\text { Considera-se apenas o acabamento. }\end{array}$ & 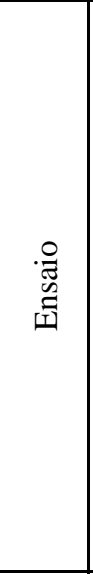 & 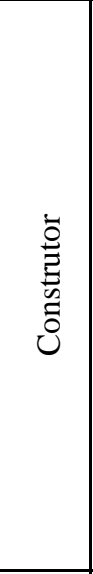 & 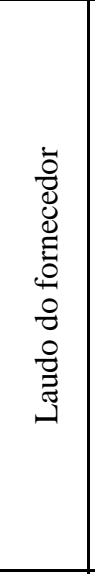 & 50 \\
\hline 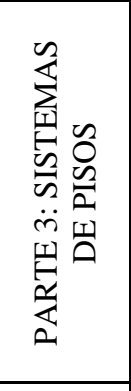 & 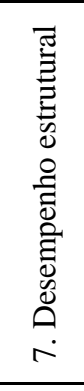 & 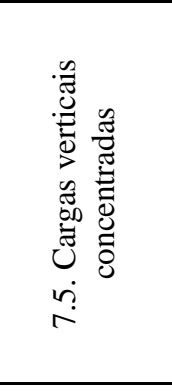 & $\begin{array}{l}\text { Os sistemas de piso não devem apresentar ruptura } \\
\text { ou qualquer outro dano, quando submetidos a } \\
\text { cargas verticais concentradas de } 1 \mathrm{kN} \text {, aplicadas } \\
\text { no ponto mais desfavorável e não apresentarem } \\
\text { deslocamentos superiores a L/250, se construídos } \\
\text { ou revestidos de material rígido, ou L/300, se } \\
\text { construídos de material dúctil. } \\
\text { Ensaio seguindo as premissas do Anexo B da } \\
\text { NBR } 15575-2 \text {. } \\
\text { Considera-se apenas o acabamento. }\end{array}$ &  & 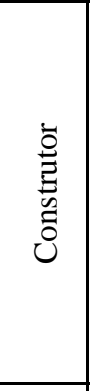 &  & 50 \\
\hline 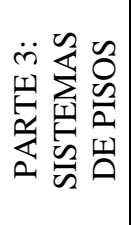 & 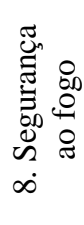 &  & \multirow{2}{*}{$\begin{array}{l}\text { 8.2.1: Avaliação da reação ao fogo da face } \\
\text { inferior do sistema de piso } \\
\text { Os critérios de avaliação da reação ao fogo da } \\
\text { face inferior do sistema de pisos (camada } \\
\text { estrutural) devem corresponder aos presentes nas } \\
\text { tabelas } 2 \text { e } 3 \text { da NBR } 15575-3 \text {. Materiais classe I, } \\
\text { como aço e concreto, atendem a este critério, já } \\
\text { os demais devem passar por ensaio. Este ensaio } \\
\text { deve ser desenvolvido com base na NBR } 9442 . \\
\text { Considera-se apenas o material. }\end{array}$} & 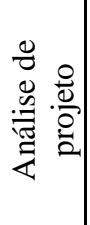 & 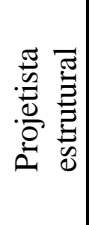 & 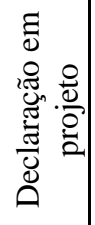 & 50 \\
\hline 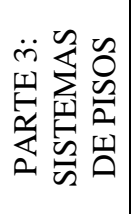 & 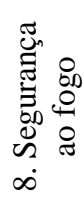 & 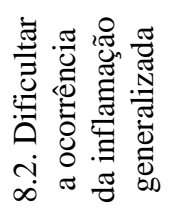 & & 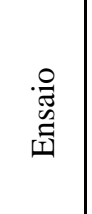 & 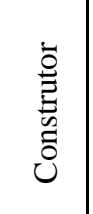 & 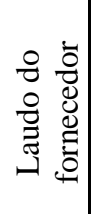 & 50 \\
\hline 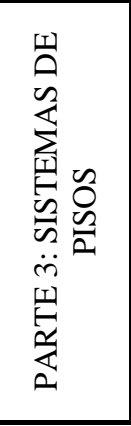 &  & 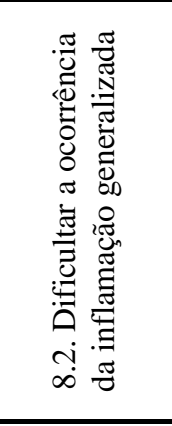 & $\begin{array}{l}\text { 8.2.3: Avaliação da reação ao fogo da face } \\
\text { superior do sistema de piso } \\
\text { Os critérios de avaliação da reação ao fogo da } \\
\text { face superior do sistema de piso (acabamento, } \\
\text { revestimento e isolamento termoacústico) devem } \\
\text { corresponder aos presentes na Tabela } 4 \text { da NBR } \\
\text { 15575-3. Materiais pétreos, como mármore, } \\
\text { granito e materiais cerâmicos são considerados } \\
\text { classe I, os demais devem passar por ensaio, para } \\
\text { definir a classe. Esse ensaio deve estar de acordo } \\
\text { com as especificações da NBR 8660. }\end{array}$ & 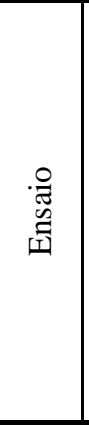 & 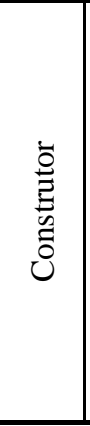 & 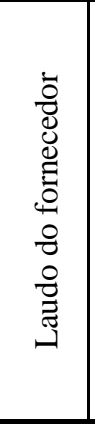 & 50 \\
\hline
\end{tabular}


Por fim, cabe ressaltar que a função primeira de um checklist, de modo geral, é auxiliar o usuário a se lembrar de todos os itens de uma tarefa ou processo que ele precisa cumprir. No caso da NBR 15575, é fundamental a adoção dessa ferramenta, tendo em vista a extensa lista de itens que a empresa precisa atender. Com o proposto nesta pesquisa, o checklist cumpre também um segundo papel, que é o de definir por quanto tempo guardar as evidências desse atendimento.

\section{Referências}

ASSOCIAÇÃO BRASILEIRA DE NORMAS TÉCNICAS. NBR 15575-1: edificações habitacionais: desempenho: parte 1: requisitos gerais. São Paulo, 2013.

ASSOCIAÇÃO BRASILEIRA DOS ESCRITÓRIOS DE ARQUITETURA. Guia para Arquitetos na aplicação da Norma de Desempenho. 56 p. Disponível em:

http://www.asbea.org.br/userfiles/manuais/d4067859bc53891dfce5e6b282485fb4.pdf. Acesso em: 9 mar. 2019.

BRASIL. Ministério das Cidades. Secretaria Nacional de Habitação. Regimento Geral. Regimento Específico da Especialidade Técnica Execução de Obras. Sistema de Avaliação da Conformidade de Empresas de Serviços e Obras da Construção Civil - SiAC, Brasília, 14 jun. 2018. Disponível em: http://pbqp-h.cidades.gov.br/download.php?doc=5dd4812f-bb7e-470e-9cae15c6d57ffe9d\&ext=.pdf\&cd=4265. Acesso em: 18 fev. 2019.

CÂMARA BRASILEIRA DA INDÚSTRIA DA CONSTRUÇÃO. Desempenho de edificações habitacionais: guia orientativo para atendimento à norma ABNT NBR 15575/2013. 2. ed. Fortaleza: Gadioli Cipolla Comunicação, 2013.

CÂMARA BRASILEIRA DA INDÚSTRIA DA CONSTRUÇÃO. Dúvidas sobre a norma de desempenho: especialistas respondem. Brasília: CBIC, 2015.

CÂMARA BRASILEIRA DA INDÚSTRIA DA CONSTRUÇÃO. Norma de desempenho: panorama atual e desafios futuros. 2016. 9 f. São Paulo: Pesquisa Setorial - Resumo executivo, CTE - Centro de Tecnologia de Edificações, 2016.

COSTELLA, M. F. et al. Avaliação da aplicação da norma de desempenho: estudo de caso em cinco empreendimentos. Revista de Engenharia Civil IMED, Chapecó, v. 4, n. 2, p. 55-74, jul./dez. 2017.

COSTELLA, M. F. Norma de desempenho de edificações: modelo de aplicação em construtoras. Curitiba: Appris, 2018.

HIPPERT, M. A. S. et al. Desempenho de Edificações Brasileiras: uma revisão da literatura. Juiz de Fora, 2018. Projeto de pesquisa de Iniciação Científica (Resultados preliminares) - Faculdade de Engenharia, Universidade Federal de Juiz de Fora, Juiz de Fora, 2018.

LAZZARINI, S. Diretrizes para controle de informação documentada gerada pela implantação da NBR 15575: dificações habitacionais: desempenho em empresas construtoras. Juiz de Fora, 2019. 125 f. Dissertação (Mestrado em Engenharia Civil) - Programa de Pós-Graduação em Ambiente Construído PROAC, Universidade Federal de Juiz de Fora, Juiz de Fora, 2019.

OKAMOTO, P. S. Os impactos da norma brasileira de desempenho sobre o processo de projeto de edificações residenciais. São Paulo, 2015. 160 f. Dissertação (Mestrado em Engenharia Civil) - Engenharia de Construção Civil e Urbana, Escola Politécnica da Universidade de São Paulo, São Paulo, 2015.

OTERO, J. A.; SPOSTO, R. M. Caracterização da atuação de construtoras e incorporadoras de Goiânia-GO frente às normas de desempenho ABNT NBR 15575:2013. In: ENCONTRO NACIONAL DE TECNOLOGIA DO AMBIENTE CONSTRUÍDO, 16., Porto Alegre, 2016. Anais [...] São Paulo: ANTAC, 2016.

PRODANOV, C. C.; FREITAS, E. C. de. Metodologia do trabalho científico: métodos e técnicas da pesquisa e do trabalho acadêmico. 2. ed. Novo Hamburgo: Feevale, 2013.

PROGRAMA BRASILEIRO DE QUALIDADE E PRODUTIVIDADE NO HABITAT. Projetos - Sistema de Avaliação da Conformidade de Serviços e Obras - SiAC. Brasília. Disponível em: http://pbqph.cidades.gov.br/projetos_siac.php. Acesso em: 18 fev. 2019. 
PROGRAMA DE INOVAÇÃO DA INDÚSTRIA DA CONSTRUÇÃO CIVIL DO CEARÁ. Análise dos critérios de atendimento à norma de desempenho ABNT NBR 15575: estudo de caso em empresas do programa Inovacon-CE. Ceará: Inovacon-CE, 2016.

SANTOS, D. de G. et al. Desempenho de edificações residenciais: projetistas e empresas construtoras. In: ENCONTRO NACIONAL DE TECNOLOGIA DO AMBIENTE CONSTRUÍDO, 16., Porto Alegre, 2016. Anais [...] São Paulo: ANTAC, 2016.

SERVIÇO NACIONAL DE APRENDIZAGEM INDUSTRIAL DE MINAS GERAIS. Manual para contratação de projetos para o desempenho de edificações habitacionais. Belo Horizonte: SENAI Departamento Regional - MG, 2016.

SILVA JÚNIOR, M. A. Parâmetros de desempenho incorporados em projetos de arquitetura com o uso de aplicativo de modelagem BIM. São Paulo, 2016. 130 f. Dissertação (Mestrado em Habitação: Planejamento e Tecnologia) - Instituto de Pesquisa Tecnológicas do Estado de São Paulo, São Paulo, 2016.

SILVA, C. A. da. Análise da vida útil estimada das edificações baseada na norma de desempenho (ABNT NBR 15.575:2013). Recife, 2016. 116 f. Dissertação (Mestrado em Engenharia Civil) Universidade Católica de Pernambuco, Recife, 2016.

YIN, R. K. Estudo de caso: planejamento e métodos. 2. ed. Porto Alegre: Bookman, 2001.

Programa de Pós-Graduação em Ambiente Construído | Universidade Federal de Juiz de Fora | Rua José Lourenço Kelmer, s/n, Campus Universitário, Bairro São Pedro | Juiz de Fora - MG - Brasil | CEP 36036-900 | Tel.: (32) 2102-6465 | E-mail: simone.lazzar@gmail.com

Maria Aparecida Steinherz Hippert

Programa de Pós-Graduação em Ambiente Construído | Universidade Federal de Juiz de Fora | E-mail: aparecida.hippert@ufjf.edu.br

\author{
Ambiente Construído \\ Revista da Associação Nacional de Tecnologia do Ambiente Construído \\ Av. Osvaldo Aranha, $99-3^{\circ}$ andar, Centro \\ Porto Alegre - RS - Brasil \\ CEP $90035-190$ \\ Telefone: +55 (51) 3308-4084 \\ Fax: +55 (51) 3308-4054 \\ www.seer.ufrgs.br/ambienteconstruido \\ E-mail: ambienteconstruido@ufrgs.br
}

